\title{
Factors Contributing to Low Postnatal Coverage in Ga East Municipality
}

\author{
Article by Oscar Vetsi \\ Disease Control Unit, Ga East Municipal Health Directorate, Ghana \\ E-mail:oscarvetsi@ymail.com
}

\begin{abstract}
s
Postnatal period is a very critical stage for both the mothers and their babies. The importance of postnatal care services has been established in various studies globally. Yet postpartum care is the most neglected aspect of women's health care, not only in developing countries but also in some developed countries. In Ghana $23 \%$ of postpartum mothers do not receive postnatal at all.

This study seeks to explore contributory factors associated with low postnatal service utilization in Ga East District of Greater Accra Region (GAR).

The study design was a cross sectional explorative and qualitative research using focus group discussions. The target population for the study were women in the reproductive age and living in the Municipality. The study used five focus group discussions to determine factors contributing to low postnatal coverage in Ga East Municipality.

A purposive sampling was employed to carry out to recruit the participants. The researcher moderated all discussions assisted by one trained assistants. The taped discussions were transcribed and the resulting texts analyzed by using thematic analysis.

The findings of the study will be communicated to both the School of Public Health and the Ghana Health Service.
\end{abstract}

Keywords: PNC; Postpartum; Postnatal; Coverage; Factors; Period.

\section{Introduction}

Studies have found that the post-partum period also known as the pueperium begins with the delivery of the baby and the placenta. The end of the post-partum period is often considered as six to eight weeks after delivery because the effect of pregnancy on many systems may have resolved by this time and these systems would have largely returned to their pre pregnancy state. However, all organs do not return to their baseline within this period. The return to baseline is not necessarily linear overtime. In some studies, some women are considered post-partum for as long as 12 months after delivery.

The need for continuum of care as a core principle of programs for maternal, new born and child health and as means to reducing maternal, new born and child death has been emphasized by recent literature.(Kerber, de Graft-Johnson, Bhutta, Okong, Starrs, \& Lawn,2007) Postnatal care services are the most neglected programme of the reproductive and child health programmes in the African region and yet a number of serious complications and majority of maternal deaths occur during the postnatal period especially in this part of the world (Ogwang., 2005,Warren Daly, Toure \& Mongi., n.d). Many African mothers and their newborns, especially those who delivery at home do not receive postnatal care (PNC). From 23 demographic health surveys (DHS), out of the two thirds of the sub-Saharan African women who delivered at home, only $13 \%$ received postnatal visit within two days of birth. According to the DHS data in Mali 85\% of women who delivered at home received no PNC and in Eritrea, $92 \%$ of women who delivered at home received PNC after six weeks of birth. (Warren et al, n.d).

It has been established that mortality can be extremely high on first and second day after birth. Although postnatal has frequently been neglected in trails, new evidence is shaping the development of the post natal package (Bang et al 2005, Haws et al 2007). (Kerber et al 2007) proposed that post natal is vital for the reduction of death among mothers and neonates and to support the adoption of healthy behaviors. Postnatal care for mothers and infants should include assessment for mother and infant to identify complications, facilitate referral and counseling in areas such as infant feeding, maternal nutrition and family planning (FP) to promote healthy behaviors (WHO 1998). For example, the highest 
risk of death for both the mother and her newborn occurs at the time of childbirth or immediately in the period of birth. It has been established that appropriate postnatal care (PNC) is critical to safeguarding maternal and new born health (Sines, Syed,Wall ,\& Worley ,2007).Of the approximately 130 million infants born annually worldwide, four million infants die in the neonatal period, representing almost $40 \%$ of deaths of children under five years of age.(Lawn, Consens \& Zupan 2005).

More than two-thirds of neonatal deaths occur in the first seven days of life and of these half die in the first twenty-four hours. (Yingar \& Ransom ,2003). This is also the case with maternal deaths where almost two-thirds tend to occur during the PNC period.(Abou Zahr \& Wardlow, 2001).Strategies to prevent and reduce neonatal deaths have been implemented worldwide,

Including the provision of postnatal care to mothers and newborns within the first 42 days of life. (Darmstadt, Bhutta, Cousens, Adam, Walker, \& de Bernis, 2005). With the dramatically increased risk of newborn deaths in the first hours and the first days of life, newborns are recommended to receive postnatal health care immediately after delivery (Sines, et al., 2007).

Health professionals are able to detect post-delivery problems including potential complication and to provide appropriate treatment promptly, during postnatal care services. In Ghana, postnatal mothers and their neonates are recommended to receive at least two adequate health care checks within the period of 0-3 days and 8-28 days after birth [GMHS 2007, GSS et al., 2009).

\section{Statement of the problem}

The utilization of postnatal care services is very important to save women and children live (WHO, 2012). Even though global maternal mortality due to pregnancy and child birth was reduced by $50 \%$ from 1990 to 2010, three hundred and fifty-eight thousand $(358,000)$ women still die from pregnancy related problem every year. Most of these deaths occur within 48 hours after birth. Also, each year 7.6 million children under age five die, (WHO, 2012).

High neonatal mortality and maternal death remain the main obstacles to attaining Millennium Development Goals (MDGs) 4 which calls for two-thirds reduction in mortality among children under five years on one hand and MDG 5 for the improvement of maternal health on the other. With less than a thousand (1000) days to the deadline to achieving the MDGs, it is of great importance that pragmatic efforts and results oriented measures are instituted.

According to the Ga East Municipal Health Management Team (MHMT) annual report 2011, although there has been some steadily increase in the PNC coverage; it is still below the national coverage. In this regard the current study, will like to find answers to this question "What are the factors contributing to low PNC coverage in Ga East Municipality?

\section{Methodology}

\section{Study type}

The study is essentially exploratory. This research design is relevant to the study because of its flexible and change adaptable nature. It is also a valuable means to seek new insight, to ask questions and to assess phenomena in a new light. Its 'two-phase' approach makes it easy to implement and straight forward to describe and report. This section therefore, presents an overview of the methods to be used in collecting and analysing the data for the study. The section further includes the description of the research design, population, sample and sampling techniques, data collection and analysis.

\section{Background of study area}

Ga-East is one of the six administrative districts in greater Accra region. Health-wise, its mission and vision is in conformity with that of the region and have been stated below; it is geographically a small district, which lies in the northeastern part of Greater Accra region. The district is bounded in the north by Akwapim south district. West by Ga west district, East by Adenta Municipality district and South by Accra metropolis. The district has a total land size of $166 \mathrm{sq} / \mathrm{km}$. it is currently made-up of four sub-districts namely; Abokobi, Haatso, Taifa, and Dome sub-districts. There are eight three communities comprising mixed settlements, i.e. urban, peri-urban and rural areas.

Two-thirds of the entire district settlement is peri-urban and rural. Due to its proximity to the region's capital its chances of benefiting from the "nation's cake" of infrastructure development is very high. 
The district falls within the trans-Saharan belt of the region with two major seasonal changes (i.e. Dry and Rainy seasons). The atmospheric condition across the district varies directly with the seasonal changes. Thus the atmosphere is mostly hazy with dry air during dry seasons and musky with humid air in rainy season. The district cannot boast of any forest due to the hilly and gravel-like nature of the land. Although, it has long duration of rainy season only few crops do well on its land. Although as a grain in a tea cup geographically, it is the third $\left(3^{\text {rd }}\right)$ densely populated district in Greater Accra region, with a projected population of 350,127 for 2005 and a growth rate of $4.5 \%$ annually.

Fair view of the district reveals public services and trading as dominant in its occupational scene, followed by farming and craftsmanship. Besides, a sizeable proportion of the working forces in the district are unemployed reflecting the high poverty level. Two major festivals, namely Dokobi is celebrated by Sessemi inhabitants and Homowo celebrated by Boi, Teiman and the other communities in conjunction with Teshie and La inhabitants.

The district has a total of thirty-six (36) health facilities, both public and private with public facilities constituting only $12 \%$ (i.e. 4), the remaining $88 \%$ (i.e. 32) being private. The Ga East Municipality lies to the North -eastern part of Greater Accra Region. It is bounded to the North by Akuapim South District, West by Ga West Municipality, East by Madina - La Nkwantang Municipality which until recently was part Ga East Municipality and to the south by Accra Metropolis. The two communities comprising mixed settlements, urban, peri-urban and rural areas. It has a population of 170,907 and a growth rate of $4.5 \%$. ( Municipal Health Annual Report 2012) Public services and trading are dominant in its occupational scene, followed by farming and craftsmanship. Besides, a sizeable proportion of the working force in the municipal is unemployed, reflecting the high poverty level and for that matter their inability to pay for the health care services offered them.

There are two festivals namely Dokobi which is celebrated by the people of Boi and Teiman in conjunction with Teshie and La inhabitants. The municipality has about sixteen (16) facilities made up of public, quasi, private and Community-based Health Planning Services (CHPS) compound. The breakdown is as follows; One ((1) public (Abokobi Health Center), One (1) quasi (Ghana Atomic Energy Commission Clinic), One (1) CHPS compound (Taifa) Thirteen(13) Private Facilities. For easy access to health care, the municipality has been zoned into CHPS zones which are manned by Community Health Officers (CHOs), as the only one public health facility that Ga East Municipality can boast of is a health center. The Municipal Health Management Team (MHMT) is collaborating well with thirteen of private facilities. (Municipal Health Annual Report 2012)

\section{Variables for the study}

The variables for the study include demographic characteristics, knowledge, threats associated with postnatal clinics and access to postnatal care.

\section{Study population}

The study population were women in their reproductive age (15-49 years) living in Ga East. This is because they are those who seek postnatal care. The study population consists of 82,805 women.

\section{Ethical consideration: permission and invitation to participate}

Permission was sought from the Municipal Director of Health Service of Ga East since my research topic was within his domain. Permission to conduct FGDs in the communities was sought from community leaders. Information about the objectives of the discussion and the purpose of the overall study were provided to each potential participant. Confidentiality with regard to their participation and anonymity with regard to their stored data were assured, and each participant was asked for her verbal consent to participate in the focus group discussion. Permission to audio-record the discussions was also sought and obtained. In the FGDs, each participant was assigned a unique pseudo-name to protect their identity. Participants did not receive any monetary incentive for participating in the discussions.

However, two cakes of soap were provided as a token of appreciation for their participation. This study was approved by the Ghana Health Service ethical review committee. 
DOI: $10.21522 /$ TIJPH.2013.05.04.Art009

ISSN: $2520-3134$

\section{Sampling}

Participants were purposively selected by the principal investigator for FGDs through Community Health Officers base on the fact that the individual has one or more children under age five, and individual's willingness to participate.

\section{Sample size}

A total of forty-one participants participated in the study.

\section{Eligibility criteria}

Inclusive criteria: all women with one or more children under five years, who are resident in the municipality for at least twelve (12) months.

\section{Data collection techniques or strategies}

Data for the study included both primary and secondary data. Focus group discussions (FGDs) were used to obtain primary data from respondents with the help of two (2) research assistants trained on the focus group discussion guide and on interview techniques. Five focus groups made up of between 8 participants in four groups and 9 participants in the other one group were conducted. Focus Group Discussion (FGD) were used to collect the data for this study because they have traditionally been employed in the social sciences and have much to offer studies on health related issues (Pope \& Mays, 2006). FGD highlight (sub) cultural values or group norms; and so makes FGD a data collection technique particularly sensitive to cultural variables. Also FGD gives a collective shared meaning through which a community sustains a particular view of some aspects of the world. (Moscovici, 1984). The FGDs were used to explore the women's subjective knowledge about postnatal care services. All FGDs were audio recorded, conducted in the Twi language, and transcribed into English and notes taken on verbal and non-verbal communication.

A prepared guide was used to ensure that discussions covered all the important themes of the study. The venues were the Reproductive and Child outreach sites for each community. During the data collection permission was sought before the notes taking and the audio-recording. Participants used fictitious names during the focus group discussion. The focus group guide was used to elicit information on the following themes - knowledge about postnatal care, source of knowledge about postnatal care, timing of postnatal care kinds of services rendered, reasons for failure to attend postnatal, risk of failure of PNC attendance, access to postnatal and improving postnatal are services. The researcher first explained the aims of the focus group sessions and established the ground rules for the sessions before discussing the issues. The participants were encouraged to freely express their views. Participants were gathered in a semi-circle around the interviewer. Questions were posed to the group, and the interviewer took responses from participants one by one; moving the digital voice recorder closer to the respondent who was speaking.

Each question was fully discussed before moving to the next question. In some cases follow up questions were asked to probe to get clearer understanding of issues. Sessions lasted between one (1) hour and one (1) hour forty-five minutes. Transcription started 24hours after the focus group discussions.

Appropriate and relevant documents were reviewed to complement the primary data sources.

\section{Data collection instrument}

A focus group discussion guide, a digital voice recorder, field notebook and a field diary were used in collecting the data.

\section{Quality control}

To ensure the quality outcome of the study, the following were done.

An independent coder was employed to code about $30 \%$ of the transcripts, selected at random, using the coding scheme of the researcher. It is expected that there should be more than $80 \%$ agreement in codes (ie the concordance rate). The data was analyzed manually, by the researcher. 


\section{Limitation of the study}

It was quite difficult getting participants especially in the urban areas where most people are always on the move. More so when people realized that they were not going to receive money for their participation, they opt out. Another limitation was that Ga East Health Administration had not upgraded their profile to reflect the municipals new status. The Municipal Public Health Nurse helped the researcher to tease out data to reflect the current status from the Municipal Health, Annual Report, 2012.

A considerable amount of information was lost due to the verbatim transcription of the five Twi focus group discussions and its translation into English.

\section{Results}

A total of forty-one people participated in the Focus Group Discussion. The demographic factors identified in this research were age, level of education, occupation and number of children of the participants. The oldest participant was 58years and the youngest 20 years old. Majority of the respondents have some education ranging from primary to tertiary education, while a few had no formal education.

Most of the participants were engaged in petty trading, with quite a sizable number being unemployed and a few of them being civil servants. More than half of respondents had between one and two children, while only a few had at least five children, with the mean number of children being three (3). Interestingly all the participants were married.

\section{Cues to action; women's knowledge about postnatal care}

Majority knew about the existence of postnatal care, so they sought for postnatal care services when they delivered. Most of them who knew about it got their information from Community Health Officers (CHOs) and Community Health Nurses (CHNs) during Home Visits and Child Welfare Clinics (CWC). The following illustrate their knowledge and source of knowledge about PNC. However, some of the participants claimed they did not know about the existence of PNC. Quite a sizable number of participant's mostly first time mothers, who had given birth to their first children even in hospitals, said they did not seek for postnatal services because they did not know about it. These responses gleaned from the discussion demonstrate their lack of knowledge about the PNC. Lack of knowledge about the PNC services could be a barrier to women's utilization of postpartum services. From the discussion it is clear that first time mothers were particularly ignorant about the PNC. It is interesting to note that Health Workers who attended to the mothers during delivery did not tell them about the PNC. This has also been reported in other studies, Dhaher et al 2007, Mrisho et al 2009, Nankwang 2004, and Titaley et al 2008).

Given the intensive sensitization by the Reproductive and Child Health Unit of the Ghana Health Service, it is not surprising that majority knew about PNC. However it was clear from the study, that first time mothers were particularly ignorant about PNC. It is interesting to note that Health Workers who attended to the mothers during delivery did not tell them about the Many of the women who participated in the research delivered in private health facilities where PNC is note emphasized because, the service is supposed to be free and so it did not make commercial sense to the private provider. Anecdotal evidence suggests that private health facility emphasize, Antenatal Care (ANC) and Supervised Delivery other than PNC. Mrisho et al. (2009) contradicted this finding in their study of women and health care providers in rural Southern Tanzania, where those who delivered at private hospital enjoyed postnatal services more as compared to those who delivered at public hospital. The timing of postnatal care is very crucial in postnatal service delivery, as the first hours, days and weeks after childbirth are dangerous times for both mother and newborn infant. Sines et al. (2007) recommended that newborns receive postnatal health care immediately after delivery. Of those women who knew about postnatal care services, majority of them did not know, how early and how often they have to seek for postnatal care services.

Most women were of the view that, postnatal care services are sought once and at six weeks, thus confusing it with the timing of Child Welfare Clinic (CWC) the reason could be because CWC begin around the same time, six weeks. This finding agrees with Mrisho et al where most women confused the PNC services with the monthly immunization. However, two of the participants, were of the view that postnatal care services are sought twice after delivery that is at two weeks and six weeks. Though 
DOI: $10.21522 /$ TIJPH.2013.05.04.Art009

ISSN: $2520-3134$

Ghanaian women are recommended to receive at least two adequate health care checks within the period of 0-3 days and 8-28 days after birth [GMHS 2007, GSS et al 2009). This was not the case from the study.

I think this is so because most women do not actually know when to seek PNC services as there was no difference between women with tertiary education and those with basic and post-basic education, concerning timing and frequency of PNC. This clearly shows that the Reproductive and Child Health Unit of the Ghana Health Service, needs to reconsider their health educational talk topics to include the timing and frequency for seeking postnatal care.

Again from the study, it was evident that most of the participants did not know of the kinds of services rendered during postnatal care. They are of the view that postnatal care is solely for their newborns, as health providers tend to pay much attention to the newborn infants as compared to the mothers, as only the mothers blood pressure are checked and a few questions asked about the mother, with the health providers assuming all is well with the postnatal woman.

This is also the case in Tanzanian, where postnatal services target the newborn with little emphasis on the mothers as revealed by Mrisho et al (2009) in their study. Participants mentioned the kinds of services rendered at postnatal care as checking of mothers' blood pressure, weighing of babies, giving of injections against tuberculosis and polio, examination of both mother and baby and counselling on the care of the newborn

\section{Perceived threats: risks to postnatal care non attendance}

On this theme the researcher used two questions to arrive at it. These questions are on disadvantages of failure to postnatal care services and what will make women to seek postnatal care.

There was a universal belief that failure to seek postnatal care could result in unfortunate consequences, the woman or her newborn infant or both of them may become sick, disabled or die from birth complications.

Despite the general belief that failure to seek postnatal care could be detrimental to both mother and baby and to a large extent the family, quite a number of the participants will only seek for

PNC services when there is something wrong with their babies or themselves

Some women will seek for postnatal care when they feel that they are at risk of losing their lives or that of their babies or they have difficulty with breastfeeding. As noted elsewhere (Dhaher et al 2008, Haws et al 2009) caesarean delivery or perennial incision women are more likely to seek PNC services.

\section{Perceived benefits: of women staying healthy and having healthy babies}

Almost all the participants believe that postnatal care services are good for the health of both the mother and the baby as it helps in early detection of any abnormality in the newborn baby and afterbirth complication of the mother for appropriate and timely treatment.

Though majority of the participants were of the view that postnatal care services were very important to both mother and the baby, they were not satisfied with the kind of services they received. With most women now viewing quality care, to include right information, good communication and attitude of health professionals as (Tunc, alp O., Hindin, M.J., Adu-Bonsaffoh, K. \&, Adanu, R. (2012), it was not surprising when majority were not satisfied with the PNC that they were offered. One person however said that postnatal is not important because the nurses did not inform the mothers at antenatal about it.

Another participant was of the view that postnatal care is not of much importance even to the health care provider, because most health care providers are most of the time, in a hurry when attending to postnatal women. I think that though most women do not know what PNC services entail, they expect more from the health care providers than what they are currently being offered. If the women know what to expect from the health care providers, the women will perhaps ask questions when some services are omitted by the health care providers. There was no difference between participants with high educational level and those with basic or no education, about the kinds of PNC services rendered to postnatal mothers. 


\section{Perceived barriers: access to postnatal care services}

Quite a number of the participants knew about the importance of postnatal care services but failed to go for the services for a number of reasons. Majority of the participants mentioned inaccessibility of the health facility as a major constraint to their PNC access. Equally worth mentioning was the quality of care they receive. Quality of care at facilities relates to issues such as negative staff attitude and the PNC care proper. Finally, financial constraints were also mentioned.

Other reasons why most women do not seek for postnatal care were identified as laziness on the part of the mother, after pains and lack of family support. One participant however said most women also use traditional medicine after birth. This finding have been reported in other studies where traditional practice is well inculcated in the postpartum period.( Mekonnen \& Mekonnen 2002, Tao et al 2009, Titaley et al 2010,Thi,L.M.,Pasandantorn,W. \& Rauyajin, O.(n.d)).

\section{Self-efficacy: women's ability to seek care}

It was evident during the focus group discussion that many women had confidence in themselves that they could seek for PNC. The 'wardrobe syndrome' is not an issue with most women in Ga East Municipality, as they do not actual mind going to the health facility with any neat dress or cloth that they have.

\section{Participant's opinion on ways of improving postnatal services in the municipality}

From the discussions, the participants made some suggestions as to how they think postnatal care could be improved, participants were of the view that availability of a public health facility, at least one district hospital, positive staff attitude, availability, of skilled personnel, quality of postnatal care, eduentertainmet on the importance of PNC services on our electronic media and skilled health providers visiting postnatal mothers at their homes to render PNC services will go a long way to improving postnatal care in the municipality.

\section{Summary}

The findings show that majority,39 $(95.1 \%)$ of the participants think that PNC is very necessary and important to both the mother, the newborn and the family as a whole but women fail to seek PNC services due to a number of reasons. From the focus group discussions it was evident that limited availability of public health facilities, the absence of doctors in Abokobi Health Center for instance is the main reason for the low utilization of not only PNC services but other health services as well. Lack of knowledge about PNC services, negative staff attitude, distance, financial constraints in terms of poverty and cost of transportation, also came up strongly as reasons for failure in seeking postnatal care services.

Other reasons were inadequate support from the family members and the use of traditional medicine. Interestingly, quite a number of participants, $8(19.5 \%)$ attributed the failure of women seeking PNC services to laziness on the part of postnatal mothers.

\section{Conclusion}

This study sought to determine the factors contributing to low PNC service utilization in Ga East Municipality. To be able to do this, a qualitative approach was used to carry out this study. The findings of the data collected through focus group discussions were presented in thematic areas and the issues discussed. Again all the variables in the socio-demographics of the participants, did not show any impact on the utilization of PNC services. The study showed that women's knowledge of postpartum care is a very essential predictor of postnatal care services utilization, especially for first time mothers. Most of the first the mothers did not seek for PNC services because they were not aware of the service. The findings also indicated that health care providers do not provide sufficient information on the merits of postnatal care and the demerits of failure to seek PNC.

Findings further showed that health care providers are not rendering quality PNC services to women as they should, for instance the physical examinations that need to be conducted during PNC are not completely done. 
DOI: $10.21522 /$ TIJPH.2013.05.04.Art009

ISSN: $2520-3134$

Most health care providers only check the blood pressure of the postpartum mothers. As a result some of the participants were not satisfied with the PNC services they received. This shows that there are shortcomings in the basic PNC services provided to postpartum women.

Finally, findings from the study revealed that accessibility in terms of availability of health facility, availability of professional health personnel, cost of transportation and distance, in addition to negative attitude of health care providers are preventing postnatal mothers, especially those who deliver at home from utilizing PNC service. Lack of social support from family members, was also enough reason for the failure of some women from seeking PNC services.

\section{Recommendations}

The recommendations made from this study are as follows:

1. Based on the findings it will be recommended that the public health facility in the municipality is provided with doctors as urgently as possible.

2. It was clear from the study that there are shortcomings in the PNC services being rendered by health care providers currently. Therefore it will be recommended that the contents of PNC services be reconsidered to meet women's needs especially emotional, psychological and physical needs.

3. It will also be recommended that all categories of health care providers are retrained on the package of PNC, Quality Assurance and Customer Care.

4. Although majority of the participants were aware of PNC, almost all of them did not know what goes into postnatal care. It will therefore be recommended that the Health Educational Unit of the Ghana Health Service, come out with educational programmes that will portray the importance of PNC and what women are to expect from the health care providers during PNC visits. It could be in the print or electronic media.

5. Best practices being practiced in other developing countries like Madagascar and Bangladesh, where trained professionals and retired midwives visit postnatal mothers regularly during the first week after delivery, could be emulated by Ghana.

6. For further research it will be recommended that views of health care professionals considering the low utilization of postnatal care are researched into.

\section{Acknowledgement}

I am grateful to Professor Anthony Mawuli Sallar; Director of Management Development Institute (MDI) West Africa, UCLA/Johnson \& Johnson (MDI), African Medical and Research Foundation (AMREF), Ghana Institute of Public Administration (GIMPA), the Graduate School of Business at the University of Cape Town (UCT) and other faculty member of MDI for their in-depth knowledge imparted into me during West Africa MDI 2015.

My sincere thanks go to Mr. Rene Kiamba (MDI) for his inspiration during and after November 2015 MDI.

Lastly to my family especially son Chief Wigglesworth Mangosothu Vetsi, and all course mates as well as other individuals for their support and inspiration.

\section{References}

[1]. Abbas, M.K. (2012).Analysis of Factors that Contribute to Utilization of Health Facilities during Labor, Delivery and Postnatal Period in Zanzibar

[2]. Abou-Zahr, C.L., \& Wardlaw, T.M. (2001). Antenatal care in developing countries: promise, achievements and missed opportunity: an analysis of trends, levels and differentials, 1990-2001. Geneva: World Health Organization; 2003.

[3]. Bang, A.T., Bang, R.A., \& Reddy, H.M. (2005). Home-based neonatal care: summary and applications of the field trial in rural. Gadchiroli, India (1993 to 2003). J Perinatol 2005; 25: 108-22

[4]. Baqui,A.H.,Ahmed,S.,Arifeen,S.E.,Darmstadt,G.L.,Mannan,I.,Rosecrans,A.M Rahman, M.S Black, R. E.(2009). Effect of timing of first postnatal care home visit on neonatal mortality in Bangladesh: a observational cohort study. BMJ 2009; 339:b2826

[5]. Becker, M.H. \& Rosenstock, I. M.: Compliance with Medical advice. In Steptoe A and Matthews A (Eds.) Health Care and Human Behaviour. London, Academic Press, 1984. 
Texila International Journal of Public Health

Volume 5, Issue 4, Dec 2017

[6]. Ching-Yu, C., Fowles, E.R., Delivery \& Walker, L.O.(2006).A study on Postpartum Maternal Health Care in the United States; A Critical Review.

[7]. Darmstadt, G.L., Bhutta, Z.A., Cousens, S., Adam, T., \& Walker, N., de Bernis, L., (2005).Lancet Neonatal Survival Steering Team. Evidence-based, cost-effective interventions: how many newborn babies can we save? Lancet. 2005; 365(9463):977-988. doi: 10.1016/S0140-6736(05)71088-6. (PudMed)(Cross Ref)

[8]. Dhaher E, Mikolajczyk RT, Maxwell AE, Kramer A (2008). Factors associated with lack of postnatal care among Palestinian women: a cross-sectional study of three clinics in the West Bank. BMC pregnancy and childbirth. 2008; 8:26. doi: 10.1186/1471-2393-8-26.

[9]. Dhakal, S., Chapman, G.N., Simkhada, P.P., van Teijlingen, E.R., \& Stephens, J., et al. (2007). Utilization of postnatal care among rural women in Nepal. BMC Pregnancy and Childbirth 2007, 7:19 doi: 10.1186/14712393-7-19.

[10]. Farr, C., Barry, S. \& Salihu, H.M (2006). Use of postpartum health services in rural Uganda: knowledge, attitudes, and barriers. J Community Health. 2006 Apr; 31(2):84-93. PMID: 16737170 [PubMed - indexed for MEDLINE]. Accessesed11/7/2012

[11]. Ghana Health Service Annual Report, 2010.Accra.

[12]. Ghana Statistical Service (GSS), Ghana Health Service (GHS), \& ICF Macro. 2009. Ghana Demographic and Health Survey 2008: Key Findings. Calverton, Maryland, USA: GSS, GHS, and ICF Macro.

[13]. Ghana Statistical Service, Health Service \& Macro International Inc. Calverton, Maryland, U.S.A. (2009. Ghana Maternal Health Survey, 2007.Accra

[14]. Haw, R.A., Mushi, K.A., Mshinda, H., Tanner, M. \& Schellenberg, D. (2009). BMC Pregnancy and Childbirth 2009, 9:10 doi: 10.1186/1471-2393-9-10.

[15]. Hochbaum, G.M. (1958).Public Participation in Medical Screening Programmes: A socio-psychological study. Public Health Service publication. Washington, D.C.

[16]. Islam, M. R., Islam, M.A. \& Banowary, B. (n.d) Journal of family Welfare Vol.55, No. 12009.

[17]. Lakhani, M. (2006) Postnatal Care: Routine Postnatal Care of Women and their babies. Royal College of General Practioners London, SW7 IPU.

[18]. Lawn, J.E., Cousens, S. \& Zupan, J., (2005). 4 million neonatal deaths: When? Where? Why? The Lancet 365: 891-900.

[19]. Matijiasevich, A., Santos, I.S., Silveira, M.S., Domingues, M.R., Barros, A.J.D., Marco, P.L., \& Barros, P.PL (2009). Inequities in maternal postnatal visits among public and private patients: 2004 Pelotas cohort study. BMC Public Health. 2009; 9: 335. doi: Â 10.1186/1471-2458-9-335.

[20]. PMCID: PMC2749044 Accessed 1/22/2013.

[21]. Maykut, P., \& Morehouse, R. (1994). Beginning Qualitative Research: A philosophical and practical guide. London: The Falmer Press.

[22]. Mekonnen, Y. \& Mekonnen, A. (2002).Utilization of Maternal Health Care Service in Ethopia. Calverton Maryland, USA: ORC Marco

[23]. Mrisho, M.,Obrist, B. ,Schellenberg, J.A. ,Haws, R.A., Mushi, A.K., Mshinda, H., Tanner, M. \& Schellenberg, D.,(2009).The use of antenatal and postnatal care; perspectives and experiences of women and health care providers in rural Southern Tanzania. BMC Pregnancy Childbirth 2009, 9; 10 doi: 10.1186/14712393-9-10.

[24]. Municipal Health Directorate Annual Report 2012, Ga East, Abokobi. Accra.

[25]. Nabukera, S.K., Witte, K., Muchunguzi, C., Bajunirwe, F., Batwala, V.K., Mulogo, E.M,

[26]. Nankwanga, A. (2004).Factors Influencing Utilization of Postnatal Services in Mulago and Mengo Hospitals Kampala, Uganda.

[27]. Ogwang, A.F., (2005). Quality of post natal care up to discharge in Mulago hospital). A dissertation submitted to school of Graduate studies in partial fulfillment of the requirement for the award of the Degree of Masters of Medicine in obstetrics and Gynecology Makerere University).

[28]. Popes. \& Mays, N. (2006). Qualitative Research in Health Care; Assessing Quality in Qualitative Research.London.BMJ.320 (7226) 50-52. 